\title{
Non-adherence to the single dose nevirapine regimen for the prevention of mother-to-child transmission of HIV in Bindura town, Zimbabwe: a cross-sectional analytic study
}

\author{
Lazarus R Kuonza*1, Clemence D Tshuma², Gerald N Shambira' and Mufuta Tshimanga'
}

\begin{abstract}
Background: The Prevention of Mother to Child Transmission of HIV (PMTCT) programme was introduced at Bindura Hospital in 2003. Seven additional satellite PMTCT clinics were set up in the district to increase service coverage but uptake of PMTCT interventions remained unsatisfactory. In this study we determined the prevalence of and factors associated with non-adherence to the single dose nevirapine (SD-NVP) regimen for PMTCT in Bindura town.

Methods: An analytic cross-sectional study was conducted in four health institutions in Bindura town. Participants were mother-baby pairs on the PMTCT programme attending routine six weeks post natal visits in the participating health institutions from March to July 2008. We interviewed 212 mothers using a structured questionnaire.

Results: The non-adherence rate to the maternal nevirapine dose was $30.7 \%$, while non-adherence to the newborn nevirapine dose was $26.9 \%$. The combined mother-baby pair nevirapine non-adherence was $42.9 \%$. Non-adherence to the maternal dose of nevirapine was associated with lack of maternal secondary education (POR $=2.38 ; 95 \% \mathrm{Cl}$ : 1.05 3.39) and multi-parity (POR $=2.66 ; 95 \% \mathrm{Cl}: 1.05-6.72$ ), while previous maternal exposure to the PMTCT programme (POR $=0.22 ; 95 \% \mathrm{Cl}: 0.08-0.57)$ and giving the mother a NVP tablet to take home during antenatal care (POR $=0.03 ; 95 \% \mathrm{Cl}$ : 0.01-0.09) were associated with improved maternal adherence to nevirapine. Non-adherence to the infant dose of nevirapine was associated with maternal non-disclosure of HIV results to sexual partner ( $\mathrm{POR}=2.75 ; 95 \% \mathrm{Cl}$ : 1.04-7.32) and home deliveries (POR $=48.76 ; 95 \% \mathrm{Cl}: 17.51-135.82$ ).

Conclusions: Non-adherence to nevirapine prophylaxis for PMTCT was high in Bindura. Ensuring institutional deliveries, encouraging self-disclosure of HIV results by the mothers to their partners and giving HIV positive mothers nevirapine doses to take home early in pregnancy all play significant roles in improving adherence to PMTCT prophylaxis.
\end{abstract}

\section{Background}

Zimbabwe has the $4^{\text {th }}$ highest rate of HIV infection in the world, with an estimated HIV prevalence of $15.6 \%$ in adults aged 15-49 years [1,2]. The HIV pandemic has increasingly affected children, resulting in the reversal of the gains that had been made in the reduction of infant and childhood morbidity and mortality in the country.

*Correspondence: Ikuonza@gmail.com

1 Department of Community Medicine, College of Health sciences, University of Zimbabwe, Harare, Zimbabwe

Full list of author information is available at the end of the article
Mother-to-child transmission of HIV (MTCT) during pregnancy, delivery, or breastfeeding accounts for more than $90 \%$ of the HIV infections in children below 15 years of age [3,4]. Without interventions, $20-45 \%$ of babies born to HIV positive women become vertically infected with HIV [5]. Studies have shown that short-course, easy-touse, and affordable antiretroviral regimens can significantly reduce MTCT of HIV. One such regimen is the single-dose nevirapine (SD-NVP) regimen, in which the mother ingests a dose of nevirapine (NVP) at the onset of labor (at least $2 \mathrm{hrs}$ before delivery) and another dose is given to the baby within $72 \mathrm{hrs}$ of birth [4,6-8]. 
In Bindura district the PMTCT programme was started in 2003 at Bindura Hospital. In 2004 seven additional satellite comprehensive PMTCT clinics were set up in the district to increase the coverage of the services. Despite these efforts, the uptake of the PMTCT interventions remained unsatisfactory. During the period January to May 20071161 mothers delivered at Bindura Hospital. Of all these mothers, only 248 (21\%) were tested for HIV before giving birth, the rest (913) had unknown HIV status and thus could not benefit from the PMTCT programme. Out of the 248 mothers who were tested for HIV before delivery, 65 (26.2\%) were HIV positive. Of these 65, only $43(66.2 \%)$ swallowed the recommended nevirapine doses before giving birth [9].

This then raised questions on why some pregnant mothers took the bold step of being tested for HIV but would not complete the recommended protocols for them to prevent the transmission of HIV to their babies.

In Zimbabwe the SD-NVP regimen remains the recommended prophylaxis for PMTCT. The government is planning to adopt more efficacious regimens, but the problems affecting the current SD-NVP regimen with regard to access, uptake and adherence, may still affect these future regimens. Identifying these problems can assist in planning the rolling out of the new PMTCT regimens. In this study we therefore set out to determine the extent of non-adherence and to identify factors associated with the non-adherence to the SD-NVP regimen in Bindura.

\section{Methods}

An analytic cross-sectional study was conducted in the four health facilities that provide comprehensive PMTCT and maternity services in Bindura town. The study population included mothers-baby pairs registered on the PMTCT programme and attended routine six-week postnatal care in these health facilities. We reviewed the health facility PMTCT registers and all registered HIV positive mothers (and their babies) who visited these heath facilities for postnatal care between March and July 2008 were enrolled into the study. We excluded mothers who were on antiretroviral therapy before giving birth. The minimum sample size was calculated as 197 mothers-baby pairs, using the formulae: $n=\left(\frac{z_{\alpha}}{\Delta}\right)^{2} p(1-p)$ [10], assuming an error risk $\left(\mathrm{z}_{\alpha}\right)$ of 1.96 , with a precision $(\Delta)$ of $\pm 5 \%$ and expecting that $15.1 \%(p)$ of the mothers would be non-adherent (as reported by Albreicht et al in the study: Predictors of non-adherence to single dose nevirapine for PMTCT in Lusaka Zambia) [11].

The mothers were interviewed using a structured questionnaire to collect information on socio-demographic, socio-economic, socio-cultural variables, knowledge on PMTCT as well as perceptions on health services being provided.

Ethical approval to conduct the study was granted by institutional review boards of the Provincial Medical Directorate (PMD) for Mashonaland Central Province, the Bindura Municipality Directorate of Health Services and the Health Studies Office of the Ministry of Health. The aim of the study was explained to all the potential participants and written consent was obtained before the interviews. Confidentiality was assured and maintained throughout the study and no identifying information was collected.

Statistical analyses were conducted using the Epi-info statistical software (CDC-Atlanta, 2007) [12]. We first performed descriptive analyses, looking at the extent of non-adherence to NVP and comparing the distribution of various characteristics among the non-adherent and adherent mother-baby-pairs. Non-adherence was defined as lack of ingestion or delayed ingestion of NVP by either the mother or the baby (delayed ingestion being taken as less than 2 hours before delivery for the mother and more than 72 hours after birth for the baby). We then performed bivariate analyses of the possible associations between non-adherence and the variables under investigation. In determining these associations prevalence odds ratios (PORs) and their 95\% confidence intervals (95\% CI) were calculated. We then conducted stratified analysis to assess for possible effect modification (interaction) and confounding. Lastly we performed logistic regression analyses where all independent variables that were significant at the 0.25 level $\left(X^{2}, p \geq 0.25\right)$ in bivariate analyses were included in the model [13], to come up with adjusted PORs and $95 \%$ CIs.

\section{Results}

We interviewed 212 mothers between March and July 2008. Of the 273 PMTCT mothers who were due to attend the six-week postnatal care in the participating health institutions during the study period, 229 (83.9\%) attended the postpartum visit. Seventeen mothers were excluded for failing to meet the inclusion criteria, 14 had been on antiretroviral therapy before giving birth while the other three indicated that they were unwilling to respond to questions. The majority of the participating mothers, 131 (61.8\%), were aged between 21 and 30 years, with a median age of 27.0 yrs $(\mathrm{Q} 1=23$; Q3 $=32)$. The mothers were largely married (formally or informally), 
Table 1: Demographic characteristics of the PMTCT mothers who participated in the study, Bindura, 2008

\begin{tabular}{|c|c|c|c|c|c|c|c|}
\hline \multirow[t]{2}{*}{ Characteristic } & \multicolumn{2}{|c|}{ Total } & \multicolumn{2}{|c|}{ Non-Adherent } & \multicolumn{2}{|c|}{ Adherent } & \multirow[t]{2}{*}{ p-value } \\
\hline & $n=212$ & $\%$ & $\mathbf{n}=91$ & (\%) & $N=121$ & (\%) & \\
\hline \multicolumn{8}{|l|}{ Place of residence } \\
\hline Urban & 114 & (53.8) & 29 & (31.9) & 85 & $(70.2)$ & $<0.001$ \\
\hline Commercial Farming areas & 41 & (19.3) & 27 & (29.7) & 14 & $(11.60$ & $<0.001$ \\
\hline Peri-urban & 27 & (12.7) & 15 & (16.5) & 12 & (9.9) & 0.15 \\
\hline Communal (rural) & 23 & $(10.8)$ & 14 & (15.4) & 9 & (7.4) & 0.06 \\
\hline Mining community & 7 & (3.3) & 6 & (6.6) & 1 & (0.8) & 0.05 \\
\hline \multicolumn{8}{|l|}{ Marital status } \\
\hline Married/co-habiting & 170 & $(80.2)$ & 70 & (76.9) & 100 & $(82.6)$ & 0.30 \\
\hline Single & 16 & (7.5) & 9 & (7.4) & 7 & (7.7) & 0.26 \\
\hline Divorced/separated & 15 & (7.1) & 10 & $(11.0)$ & 5 & $(4.1)$ & 0.09 \\
\hline Widowed & 11 & (5.2) & 4 & (4.4) & 7 & $(5.8)$ & 0.76 \\
\hline \multicolumn{8}{|c|}{ Highest level of education attained } \\
\hline Up-to primary & 62 & (29.2) & 42 & $(46.2)$ & 20 & $(16.6)$ & $<0.001$ \\
\hline Secondary (up-to form 4) & 138 & $(65.1)$ & 46 & $(50.6)$ & 92 & $(76.0)$ & $<0.001$ \\
\hline Secondary (Form 5 and 6) & 10 & (4.7) & 3 & (3.3) & 7 & (5.8) & 0.40 \\
\hline Tertiary & 2 & (0.9) & 0 & (0) & 2 & (1.7) & 0.22 \\
\hline \multicolumn{8}{|l|}{ Employment status } \\
\hline Formally employed & 26 & (12.3) & 4 & (4.4) & 22 & $(18.2)$ & 0.002 \\
\hline Informally employed & 37 & (17.5) & 18 & (19.8) & 19 & $(15.7)$ & 0.44 \\
\hline Not employed & 149 & (70.3) & 69 & (75.8) & 80 & (66.1) & 0.13 \\
\hline
\end{tabular}

$170(80.2 \%)$ and most, 150 (70.8\%), had attained at least secondary education. Of the 212 mothers only 63 (29.7\%) were gainfully employed (Table 1).

\section{Maternal adherence to nevirapine}

Out of the 212 mothers, 36 (17.0\%) did not swallow nevirapine doses before they gave birth. Of the 176 mothers who swallowed the nevirapine doses, 29 (16.5\%) swallowed the tablets less than the recommended two hours before they delivered. This calculates to a maternal nonadherence rate of $65 / 212(30.7 \%)$, taking into consideration the timing of the single-dose nevirapine tablet intake (Table 2).

\section{Infant adherence to nevirapine}

Out of the 212 babies, 42 (19.8\%) of them did not swallow nevirapine after birth. Of the 170 babies that swallowed the nevirapine, 15 (8.8\%) took the dose after the recommended 72 hours of birth. This gives an infant nevirapine non-adherence rate of 57/212 (26.9\%), after adjusting for the timing of the nevirapine intake (Table 2).
Mother-baby pair adherence to nevirapine

Mother-baby pairs where either the mother or the baby or both failed to swallow nevirapine doses were 53 (25.0\%), but when taking into consideration the recommended time frames of swallowing the nevirapine doses, $91(42.9 \%)$ of the mother-baby pairs were non-adherent (Table 2).

\section{Nevirapine accessibility and maternal adherence}

Of the 212 mothers, 178 (84.0\%) were given nevirapine tablets to take home during antenatal care (ANC). Among the 34 mothers who were not given nevirapine tablets during ANC, 20 (58.8\%) did not ingest nevirapine before delivery and 14 (6.6\%) got the nevirapine doses during labour. Of those who got the NVP tablet during labor, $71.4 \%$ ingested the doses less than 2 hrs before giving birth. (Figure 1)

Also of note was that among the 178 mothers who received the nevirapine tablets during ANC, 16 (9.0\%) did not ingest the tablets before giving birth. Reasons given for not ingesting the NVP include forgetting to take tablet 
(4/16), misplacing the tablet (6/16), being away from home at onset of labour (4/16), labour progressed too fast $(2 / 16)$ and that the church advised against taking tablet $(1 / 16)$.

\section{Place of delivery and nevirapine adherence}

Comparing adherence by place of delivery, 52.7\% (48/91) of deliveries among the non-adherent group took place at home, compared to $5.0 \%(6 / 121)$ of deliveries among the adherent group. The reasons given for delivering at home ( $n=54$ ) include the unavailability of transport (42.6\%), inability to afford paying for the transport (18.5\%), clinic was closed (14.8\%)], labour progressed too fast $(7.4 \%)]$ and that the church discouraged them from going to the hospital (3.7\%).

Among the home deliveries ( $\mathrm{n}=54)$, most $(91.7 \%)$ of the non-adherence was of the infant NVP dose. Of the 42 infants that did not get nevirapine after birth, $76.2 \%$ were born at home. The reasons given for the babies not getting NVP included the clinic being too far (66.7\%), mother not knowing that the baby was supposed to get NVP (11.9\%), the baby was ill after birth $(9.5 \%)$, the clinic was closed (4.8\%) and husband refused (4.8\%).

\section{Self-disclosure of HIV results and nevirapine adherence}

More than half, $56.2 \%$, of the mothers in the adherent group disclosed their HIV results to their partners compared to only $37.4 \%$ of the mothers in the non-adherent group. Furthermore, $73.6 \%$ of the mothers in the adherent group disclosed their HIV results to other people (who were not their partners), compared to $57.1 \%$ of the mothers in the adherent group.

\section{Ability to afford paying for ANC services and nevirapine adherence}

The majority (93.9\%) of the 212 mothers were asked to pay for antenatal services. Only $53.0 \%$ of the mothers in the non-adherent group indicated that they could afford paying the ANC charges, compared to $79.3 \%$ of the mothers in the adherent group.

\section{Factors associated with nevirapine non-adherence: bivariate analyses}

Mother-baby pair non-adherence to nevirapine was associated with residing in a farming/rural settlement, inability to afford paying for ANC services, lack of maternal secondary education, staying with in-laws in the same household at the time of delivery, belonging to a religion not allowing the use of modern medicine, maternal use of traditional herbs during pregnancy, maternal non-disclosure of HIV results to partner, making less than three antenatal attendances, and giving birth at home. Previous maternal exposure to PMTCT and giving the mother a nevirapine tablet to take home during antenatal care were associated with reduced risk of non-adherence. We also looked at maternal employment status and multi-parity

Table 2: Prevalence of non-adherence to the maternal and newborn single doses of nevirapine in Bindura, 2008

\begin{tabular}{|c|c|c|c|}
\hline \multirow[t]{2}{*}{ Adherence Characteristics } & \multicolumn{2}{|c|}{ Frequency } & \multirow[t]{2}{*}{$95 \% \mathrm{Cl}$} \\
\hline & $\mathbf{n}=\mathbf{2 1 2}$ & $\%$ & \\
\hline \multicolumn{4}{|l|}{ Maternal nevirapine dose } \\
\hline Swallowed nevirapine at least 2 hrs before delivery & 147 & 69.3 & 62.9-75.3 \\
\hline Swallowed nevirapine less than 2 hrs before delivery & 29 & 13.7 & 9.5-18.8 \\
\hline Did not swallow nevirapine before delivery & 36 & 17.0 & 12.4-22.5 \\
\hline Total maternal non-adherence to NVP & 65 & 30.7 & 24.7-37.1 \\
\hline \multicolumn{4}{|l|}{ Newborn nevirapine dose } \\
\hline Swallowed nevirapine within 72 hrs of birth & 155 & 73.1 & $66.8-78.8$ \\
\hline Swallowed the nevirapine more than $72 \mathrm{hrs}$ after birth & 15 & 7.1 & 4.2-11.2 \\
\hline Did not swallow nevirapine after birth & 42 & 19.8 & $14.9-25.6$ \\
\hline Total newborn baby non-adherence to nevirapine & 57 & 26.9 & 21.2-33.2 \\
\hline \multicolumn{4}{|l|}{ Combined maternal-infant nevirapine doses } \\
\hline Mother, baby or both took NVP within recommended time & 121 & 57.1 & $50.3-63.6$ \\
\hline Mother, baby or both took NVP outside recommended time & 25 & 11.8 & 8.0-16.7 \\
\hline Mother, baby or both did not swallow nevirapine & 66 & 31.1 & 25.2-37.6 \\
\hline Combined mother-baby non-adherence to NVP & 91 & 42.9 & 36.4-49.7 \\
\hline
\end{tabular}


but these were not associated with mother-baby pair non-adherence on bivariate analysis. (Table 3).

On stratified analysis, the mother's education level modified the association between the maternal employment status and non-adherence to NVP. Unemployed mothers who had attained secondary education were less associated with non-adherence (POR $=0.11,95 \% \mathrm{CI}$ : 0.01 $0.87)$ than unemployed mothers who had not attained secondary education $(\mathrm{POR}=3.36,95 \% \mathrm{CI}: 1.43-7.91)$. Distance from home to the nearest health facility also modified the association between the number of ANC sessions attended and non-adherence to nevirapine. Mothers who attended more than two ANC sessions and stayed within $5 \mathrm{~km}$ of a health facility were less likely to be non-adherent $(\mathrm{POR}=0.07,95 \% \mathrm{CI}: 0.01-0.58)$ than those who attended more than two ANC sessions but resided more than $5 \mathrm{~km}$ from a health facility $(\mathrm{POR}=1.09,95 \% \mathrm{CI}$ : 0.29-4.12).

\section{Factors associated with nevirapine non-adherence: logistic regression analyses}

Lack of maternal secondary education $(\mathrm{POR}=2.58$, 95\%CI: 1.11-6.00) and home deliveries $(\mathrm{POR}=24.87$, 95\%CI: 8.37-73.93) were independently associated with mother-baby pair non-adherence to nevirapine, while previous maternal exposure to PMTCT $(\mathrm{POR}=0.17$, 95\%CI: $0.07-0.44)$ and giving the mother a nevirapine tablet during antenatal care (POR $=0.06,95 \% \mathrm{CI}$ : 0.020.21 ) independently reduced the non-adherence. (Table 4)

Further logistic regression analyses were done after splitting the non-adherence into the maternal and infant SD-NVP components. Maternal non-adherence to NVP was independently associated with lack of maternal sec-

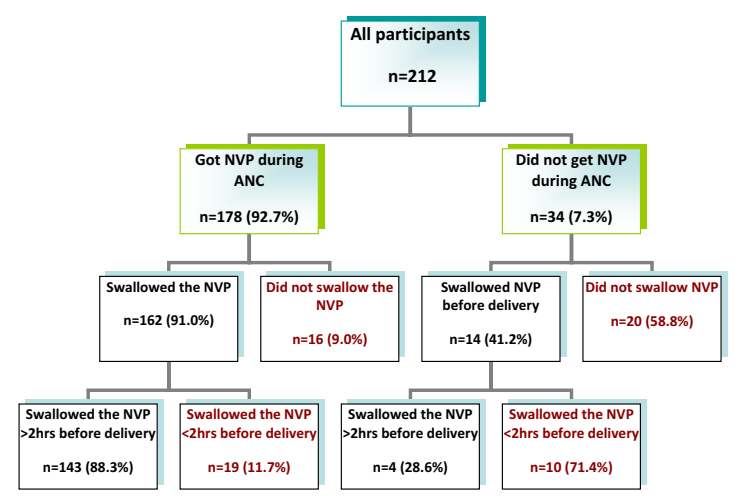

Figure 1 The patterns of maternal nevirapine non-adherence in relation to the accessibity of the maternal dose of nevirapine, Bindura, 2008. The flow diagram shows the adherence patterns of the mothers with reference to whether or not they received the nevirapine tablet during antenatal care (before the onset of labour). ondary education $(\mathrm{POR}=2.38 ; 95 \% \mathrm{CI}: 1.05-3.39)$ and multi-parity $(\mathrm{POR}=2.66 ; 95 \% \mathrm{CI}: 1.05-6.72)$ while previous maternal exposure to PMTCT $(\mathrm{POR}=0.22 ; 95 \% \mathrm{CI}$ : 0.08-0.57) and giving the mother a NVP tablet to take home during ANC (POR = 0.03; 95\%CI: 0.01-0.09) independently reduced maternal non-adherence. Infant nonadherence to nevirapine was associated with maternal non-disclosure of HIV results to sexual partner $(\mathrm{POR}=$ 2.75; 95\%CI: 1.04-7.32) home deliveries $(\mathrm{POR}=48.76$; 95\%CI: 17.51-135.82). (Table 4)

\section{Availability of resources for PMTCT}

Drugs for PMTCT prophylaxis (nevirapine tablets and nevirapine suspension) and rapid HIV testing kits were available in all the four participating health facilities throughout the study period. Each of the four health centres had at least two nurses trained on PMTCT working in the PMTCT sections, though there was a general shortages of nurses in the institutions.

\section{Discussion}

Non-adherence to the SD-NVP regimen was high in Bindura, compared to some previous studies $[11,14]$ though it was comparable to one Kenyan study where they found non-adherence rates of up-to 55\% [15]. The high nonadherence in our study was probably because our definition of non-adherence included the ingestion of a NVP dose outside the recommended times. Some previous studies defined non-adherence only as the failure to ingest NVP [11,14]. Successful PMTCT prophylaxis also depends on the timing of the NVP ingestion. If the maternal NVP dose is ingested less than 2 hours before delivery the concentration in the blood may not reach enough therapeutic levels before giving birth and if the infant NVP dose is swallowed after 72 hours of birth the baby may not get the full benefits of the drug [16,17]. It is therefore important to consider the timing of the NVP intake when looking at adherence to the NVP regimen. While most previous studies looked at adherence only to the maternal NVP dose, our study defined non adherence looking at both the maternal and the infant doses of NVP. The infant dose of NVP is equally important for the regimen to be effective and thus the prophylaxis cannot be considered complete without administration of the infant NVP dose. A few studies have also looked at both maternal and infant adherence to PMTCT prophylaxis $[11,18]$.

Of concern was that most babies born at home did not receive their NVP doses or received them too late. We attributed this to cultural practices in the studied population; newborn babies are confined within the house until the shedding of the umbilical cord stump, which usually takes about a week. The low self-disclosure of HIV results by the HIV positive mother also makes it difficult for her to convince the partner or the relatives of the need to take 
Table 3: Factors associated with non-adherence to the nevirapine prophylaxis in Bindura: Bivariate analyses

\begin{tabular}{|c|c|c|c|c|c|c|}
\hline \multirow[t]{3}{*}{ Variable } & \multicolumn{4}{|c|}{ SD-NVP Adherence status } & \multirow[t]{3}{*}{ POR } & \multirow[t]{3}{*}{$95 \% \mathrm{Cl}$} \\
\hline & \multicolumn{2}{|c|}{ Non-Adherent } & \multicolumn{2}{|c|}{ Adherent } & & \\
\hline & $\mathbf{n}=91$ & $(\%)$ & $n=121$ & (\%) & & \\
\hline Resides in a farming or rural settlement & 41 & $(45.1)$ & 23 & $(19.0)$ & 3.49 & 1.89-6.45 \\
\hline Unable to afford paying for health services & 39 & $(42.9)$ & 24 & $(19.8)$ & 3.40 & $1.82-6.33$ \\
\hline No maternal secondary education & 42 & $(46.2)$ & 20 & $(16.5)$ & 4.33 & $2.30-8.15$ \\
\hline Stays with in-laws in same household & 20 & $(22.0)$ & 14 & $(11.6)$ & 2.15 & $1.02-4.54$ \\
\hline Belongs to a restrictive religion & 31 & $(34.1)$ & 23 & $(19.0)$ & 2.20 & 1.17-4.12 \\
\hline Used herbal medicine during pregnancy & 29 & $(31.9)$ & 12 & (9.9) & 4.25 & 2.02-8.92 \\
\hline Did not disclose HIV status to partner & 57 & $(62.6)$ & 53 & $(43.8)$ & 2.15 & 1.23-3.75 \\
\hline Attended less than three ANC sessions & 14 & $(15.4)$ & 5 & $(4.1)$ & 4.22 & $1.46-12.19$ \\
\hline Delivered at home & 48 & $(52.7)$ & 6 & $(5.0)$ & 21.40 & 8.54-53.59 \\
\hline Exposed to PMTCT in previous pregnancy & 17 & $(18.7)$ & 56 & $(46.3)$ & 0.27 & $0.14-0.50$ \\
\hline Received a nevirapine tablet during ANC & 61 & $(67.0)$ & 117 & $(96.7)$ & 0.07 & $0.02-0.20$ \\
\hline Mother not gainfully employed & 68 & $(74.7)$ & 80 & $(66.1)$ & 1.16 & $0.84-3.10$ \\
\hline Multi-parity ( $4^{\text {th }}$ child and above) & 25 & $(27.5)$ & 21 & $(17.4)$ & 1.80 & $0.93-3.48$ \\
\hline
\end{tabular}

the baby to the clinic for the NVP dose before the week lapses. Other studies have also reported an association between home deliveries and babies missing their NVP doses $[19,20]$.

Non-adherence to the maternal dose of NVP was more than twice higher among mothers who had no secondary education. Maternal education enhances communication between the mother and healthcare providers and also improves retention of provided information, leading to better implementation of recommended interventions. Education also empowers the woman to have autonomy in making important decisions without relying on other people. Similar findings have been reported in previous studies $[11,19]$.

NVP non-adherence was four times higher among mothers who attended less than three antenatal sessions during pregnancy. Attending more ANC sessions offers more opportunities for healthcare providers to reinforce issues such as the importance of taking the NVP at the recommended times, the importance of delivering institutionally, the need to take the baby to the clinic in the event that birth takes place at home, and others which have a bearing on adherence to NVP prophylaxis. Investigators in a similar study in Rwanda also found an association between non-adherence to PMTCT protocols and attending few ANC sessions [19].

Maternal non-adherence to NVP was almost three times higher in multi-parous mothers. Such women usually experience precipitate labour pains which are often detected late, resulting in delayed ingestion of prophylactic doses. Similar findings were reported in Zambia [11].

Giving the mothers NVP tablets to take home during ANC improved adherence. The woman who gets NVP in advance can ingest the pill even if she gives birth at home. Also among the mothers who deliver in health institutions, those who get the NVP in advance are more likely to ingest the tablets on time than those who wait to take the NVP doses on arrival to the hospital labour ward.

There are some limitations in this study that are worth noting. Our measurement of non-adherence relied on accurate reporting by the mother and could have been affected by recall bias since some of the mothers delivered more than 6 weeks prior to the interviews, and their records did not indicate the timing of NVP ingestion. It is also possible that some women who failed to ingest their NVP doses could have falsely claimed otherwise, making the results to underestimate the prevalence of non-adherence. Lastly, this study only looked at mothers who reported for postnatal care, there is the possibility that those women who did not attend postnatal care could be more non-adherent, possibly underestimating the true non-adherence.

\section{Conclusions}

Non-adherence to the SD-NVP regimen was high in Bindura. Giving the HIV positive mother a nevirapine dose to take home during antenatal care, giving birth in health institutions and self disclosure of HIV results by the mother to the partner were associated with reduced nevi- 
Table 4: Factors associated with non-adherence to the SD-NVP regimen in Bindura: Logistic regression analyses

\begin{tabular}{lcc}
\hline Risk Factor & POR & $95 \%$ Cl \\
\hline Combined mother-baby pair non-adherence to nevirapine & & $1.11-6.00$ \\
No maternal secondary education & 2.58 & $8.37-73.93$ \\
Delivered at home (out of the health system) & 24.87 & $0.07-0.44$ \\
Exposed to PMTCT in previous pregnancy (s) & 0.17 & $0.02-0.21$ \\
Mother given a nevirapine tablet to take home during ANC & 0.06 & $1.05-3.39$ \\
Non-adherence to the maternal dose of nevirapine & & $1.05-6.72$ \\
No maternal secondary education & 2.38 & $0.01-0.09$ \\
Multi-parity (4th baby and above) & 2.66 & $0.08-0.57$ \\
Mother given a nevirapine tablet to take home during ANC & 0.03 & 0.22 \\
Exposed to PMTCT in previous pregnancy (s) & & $17.51-135.82$ \\
Non-adherence to the infant dose of nevirapine & & $1.04-7.32$ \\
Born at home (out of the health system) & 48.76 & 2.75 \\
\hline Mother did not disclose HIV results to partner & & \\
\hline
\end{tabular}

rapine non-adherence. Nurses working in the PMTCT clinics should ensure that HIV positive mothers are given nevirapine tablets at first contact, regardless of the stage of the pregnancy. Health promotion should be intensified at the community level to encourage ANC attendance and institutional deliveries. The government should consider adopting a policy of dispensing infant NVP doses during $\mathrm{ANC}$, as is done for the maternal dose, and the possibility of incorporating traditional birth attendants into the PMTCT programme, so as to increase access to the ARV prophylaxis.

\section{Abbreviations}

ANC: Antenatal Care; ARV: Antiretroviral; CDC: Centers for Disease Control and Prevention (in Atlanta); Epi Info: Epidemiological Information System; HIV: Human Immunodeficiency Virus; NVP: Nevirapine; PMD: Provincial Medical Director; PMTCT: Prevention of Mother-to-Child Transmission of HIV; POR: Prevalence Odds Ratio; SD-NVP: Single Dose Nevirapine.

\section{Competing interests}

The authors declare that they have no competing interests.

\section{Authors' contributions}

LRK participated in developing the study concept, designing the study, acquisition of data, statistical analysis and drafting the manuscript. CDT participated in the design of the study and the acquisition of data. GNS contributed to designing of the study, seeking ethical approval, analysis of data and the revision of the manuscript. MT was involved in design, analysis and interpretation of data. All authors read and approved the final manuscript.

\section{Acknowledgements}

The authors would like to acknowledge the Centers for Disease Control and Prevention (CDC-Atlanta) for providing technical assistance during the study.

\section{Author Details}

'Department of Community Medicine, College of Health sciences, University of Zimbabwe, Harare, Zimbabwe and 2Ministry of Health and Child Welfare, Mashonaland Central Province, Bindura, Zimbabwe

Received: 16 May 2009 Accepted: 28 April 2010

Published: 28 April 2010

\section{References}

1. United Nations Development Programme in Zimbabwe (UNDP): HIV \& AIDS. [http://www.undp.org.zw/what-we-do/hiv-andaids.html?3a1ed061a28f8a5e62fd4865066ea7fa=dirxelcs]. Cited 9/08/ 2008

2. United Nations Children's Fund (UNICEF) Press Centre: Zimbabwe's HIV Infection rate continues to fall (October 2007). [http://www.unicef.org/ infobycountry/media 41603.html]. Cited on 09 August 9, 2008, at 1600 hrs

3. Ministry of Health and Child Welfare, Zimbabwe: The Zimbabwe Programme for Prevention of Mother to Child Transmission of HIV 2005 Annual Report Harare, Zimbabwe; 2006

4. Centers for Disease Control and Prevention: Mother - to - Child (Perinatal) HIV Transmission and Prevention. CDC HIV/AIDS Fact Sheet 2006 [http://www.cdc.gov/hiv/]. cited on 27/09/2007

5. De Cock KM, Fowler MG, Mercier E, de Vincenzi I, Saba J, HoffE, Alnwick DJ, Rogers M, Shaffer N: Prevention of Mother-to-Child HIV Transmission in Resource-Poor Countries: Translating Research Into Policy and Practice. JAMA 2000, 283(9):1175-1182.

6. Jackson JB, Musoke P, Fleming T, Guay LA, Bagenda D, Allen M, Nakabiito C, Sherman J, Bakaki P, Owor M, Ducar C, Deseyve M, Mwatha A, Emel L, Duefield C, Mirochnick M, Fowler MG, Mofenson L, Miotti P, Gigliotti M, Bray D, Mmiro F: Intra-partum and neonatal single-dose nevirapine compared with zidovudine for prevention of mother-to-child transmission of HIV-1 in Kampala, Uganda: 18-month follow-up of the HIVNET 012 randomized trial. Lancet 2003, 362(9387):859-68.

7. Guay LA, Musoke P, Fleming T, Bagenda D, Allen M, Nakabiito C, Sherman J, Bakaki P, Ducar C, Deseyve M, Emel L, Mirochnick M, Fowler MG, Mofenson L, Miotti P, Dransfield K, Bray D, Mmiro F, Jackson JB: Intrapartum and neonatal single dose Nevirapine compared with Zidovudine for prevention of mother to child transmission of HIV-1 in 
Kampala Uganda: HIVNET 012 randomized trial. The Lancet 1999, 354(9181):795-802

8. Connor EM, Sperling RS, Gelber R, Kiselev PI, Scott G, O'Sullivan MJ, VanDyke R, Bey M, Shearer W, Jacobson RL, Jimenez E, O'Neill E, Bazin B, Delfraissy J, Culnane M, Coombs R, Elkins M, Moye J, Stratton P, Balsley J: Reduction of maternal-infant transmission of human immunodeficiency virus type 1 with zidovudine treatment: Paediatric AIDS Clinical Trials Group Protocol 076 Study Group. NEJM 1994, 331(18):

9. Provincial Health Information Records, Mashonaland Central Province. Bindura, Zimbabwe, Annual Health Profile 2007.

10. Cochran WG: Sampling Techniques 2nd edition. John Wiley and Sons, Inc New York; 1963.

11. Albrecht S, Semrau K, Kasonde P, Sinkala M, Kankosa C, Vwalika C, Aldrovandi GM, Thea DM, Kuhn L: Predictors of non- adherence to single dose nevirapine therapy for the prevention of mother to child transmission of HIV in Zambia. AIDS 2006, 41(1):114-118.

12. Centers for Disease Control Prevention: Epi-Info Version 3.4.1 Atlanta Georgia; 2007.

13. Centers for Disease Control and Prevention: Logistic Regression. Advanced Management and Analysis of Data using Epi Info for Windows: Risk Factors for Sexually Transmitted Infections in Kuwadzana Zimbabwe 2006:101 [http://www.cdc.gov/cogh/DGPHCD/training/pdf/ Avanced management manual.pdf]. CDC Atlanta

14. Stringer JS, Sinkala M, Stout JP, Goldernberg RL, Acosta EP, Chapman V, Kumwenda-Phiri R, Vermund SHI: Comparison of two strategies for administering nevirapine to prevent perinatal HIV transmission in high-prevalence, resource-poor settings, Zambia. AIDS 2003, 32(5):506-13.

15. Farquhar C, Kiarie JN, Richardson BA, Kaburu MN, John FN, Nduati RW, Mbori-Ngacha, John-Stewart GC: Antenatal couple counseling increases uptake of interventions to prevent HIV-1 transmission. AIDS 2004, 37(5):1620-1626.

16. Mirochnick M, Siminski S, Fenton T: Nevirapine Pharmacokinetics in Pregnant Women and in their Infants Following In-utero Exposure. Pediatric Infectious Diseases Journal 2001, 20:803-805.

17. Musoke $P$, Guay L, Bagenda D: A phase I study of the safety and pharmacokinetics of nevirapine in HIV-1 infected pregnant Ugandan women and their neonates. AIDS 1999, 13:479-486.

18. Stringer JSA, Sinkala M, Maclean CC, Levy J, Kankasa C, DeGroot A, Stringer EM, Acosta EP, Goldenberg RL, Vermund SH: Effectiveness of a city-wide program to prevent mother-to-child HIV transmission in Lusaka, Zambia. AIDS 2005, 19:1309-1315.

19. Anita A, Delvaux T, Elul B, Ndagije F, Roberfroid D, Munyana E, Nyiransabimana M, Mugenzi C, Bosch JVP, Mugisha V, Nizeyimana V Sahabo R: Evaluation of Access to and Utilization of Services for the Prevention of Mother-to-Child Transmission (PMTCT) of HIV in Rwanda - Summary Report. Ministry of Health. Rwanda; 2007.

20. Kasenga F, Hurtig AK, Emmelin M: Home Deliveries: Implications for adherence to NVP in a PMTCT programme in Rural Malawi. AIDS Care 2007, 19(5):646-52.

Pre-publication history

The pre-publication history for this paper can be accessed here: http://www.biomedcentral.com/1471-2458/10/218/prepub

doi: $10.1186 / 1471-2458-10-218$

Cite this article as: Kuonza et al., Non-adherence to the single dose nevirapine regimen for the prevention of mother-to-child transmission of HIV in Bindura town, Zimbabwe: a cross-sectional analytic study BMC Public Health 2010, 10:218

\section{Submit your next manuscript to BioMed Central} and take full advantage of:

- Convenient online submission

- Thorough peer review

- No space constraints or color figure charges

- Immediate publication on acceptance

- Inclusion in PubMed, CAS, Scopus and Google Scholar

- Research which is freely available for redistribution

Submit your manuscript at www.biomedcentral.com/submit
C Biomed Central 